\title{
Clinicoradiological Profile of Patients with Hydropneumothorax: A Prospective Study of a Hospital Population in Northern India
}

\author{
Saurabh Kumar Singh, Pratibha Yadav, Bhupendra Jatav, Kamlesh Kumar Tiwari \\ Department of Respiratory Medicine, Gajra Raja Medical College and Jayarogya Group of Hospitals, Gwalior, Madhya Pradesh, India
}

\section{Abstract}

Background: Hydropneumothorax is defined as the presence of air and liquid (pus, fluid, or blood) in the pleural cavity, and it carries significant morbidity. Aim: The aim of the study was to explore the demographic and clinical-radiological characteristics of patients with hydropneumothorax. Patients and Methods: This study was conducted in the tertiary care center of northern India. Patients diagnosed with hydropneumothorax between January 2017 and December 2019 were included in the study. Sociodemographic characteristics, causes, symptoms and signs, and X-ray findings were collected and analyzed prospectively. Results: Fifty-two patients with hydropneumothorax were included in the study, 39 of whom were male. The mean age of patients was $34.17 \pm 11.6$ years. Dyspnea and cough were the most common findings in $50(96.2 \%)$ and $49(94.2 \%)$ patients, respectively. Fever was seen in $47(90.3 \%)$, chest pain in 48 (92.3\%), weight loss and loss of appetite in $30(57.7 \%)$ patients, and hemoptysis in $11(21.2 \%)$ patients. Cavitation was the most common chest X-ray finding seen in $34(65.4 \%)$ cases. Tuberculosis (61.5\%) was the most common cause of hydropneumothorax. For the management of hydropneumothorax, an underwater intercostal tube drain (ICD) was inserted in all the patients. The mean duration of intercostal drainage (ICD) in 51 patients was $21.3 \pm 10.6$ days. Conclusion: Patients of hydropneumothorax presenting with symptoms of respiratory distress required a prolonged period of chest tube drainage and usually showed a good response to the treatment.

Keywords: Dyspnea, hydropneumothorax, intercostal tube drain, tuberculosis

\section{INTRODUCTION}

The abnormal presence of air and liquid (pus, fluid, or blood) in the pleural cavity is known as hydropneumothorax. On the erect chest X-ray, it appears as radiodense lower pleural space, radiolucent upper pleural space, and air/fluid level at their interface. ${ }^{[1]}$ This may be associated with the primary benign infection and may/may not have associated parenchymal involvement. It has been reported secondary to thoracocentesis, thoracic trauma, esophagopleural fistula, or bronchopleural fistula. ${ }^{[2]}$ Although the diagnosis is confirmed radiologically, clinically, it may be suspected by demonstrating succussion splash, immediate shifting dullness, straight-line dullness, and coin test. ${ }^{[3,4]}$

There has been tremendous advancement in the diagnosis and management of pleural diseases, but still, there is limited literature on hydropneumothorax. Therefore, our study was aimed to explore the signs and symptoms, causes, and management of patients with hydropneumothorax.

\begin{tabular}{|l|l|}
\hline \multicolumn{2}{|c|}{ Access this article online } \\
\hline Quick Response Code: & Website: \\
\hline & www.ijrc.in \\
\cline { 2 - 2 } & \\
\hline
\end{tabular}

\section{Patients and Methods}

This prospective and descriptive study was done at the department of respiratory medicine, a tertiary care teaching hospital in northern India between January 2017 and December 2019. Ethical clearance was approved by the institutional ethical committee. All patients $\geq 12$ years old with a diagnosis of hydropneumothorax were included in the study. Patients with traumatic or iatrogenic hydropneumothorax were also excluded from the study.

Address for correspondence: Dr. Saurabh Kumar Singh, Department of Respiratory Medicine, Gajra Raja Medical College and Jayarogya Group of Hospitals, Gwalior - 474 009, Madhya Pradesh, India. E-mail: doctorsaurabhsingh@gmail.com

This is an open access journal, and articles are distributed under the terms of the Creative Commons Attribution-NonCommercial-ShareAlike 4.0 License, which allows others to remix, tweak, and build upon the work non-commercially, as long as appropriate credit is given and the new creations are licensed under the identical terms.

For reprints contact: WKHLRPMedknow_reprints@wolterskluwer.com

How to cite this article: Singh SK, Yadav P, Jatav B, Tiwari KK. Clinicoradiological profile of patients with hydropneumothorax: A prospective study of a hospital population in Northern India. Indian $\mathrm{J}$ Respir Care 2021;10:53-6.

Received: $12-08-2020$ Accepted: 08-10-2020

Revised: 24-09-2020 Published: $31-01-2021$ 
Particulars of the patients were recorded in full. A detailed record of the presenting symptoms such as fever, cough, weight loss, loss of appetite, and hemoptysis was made. History of contact with tubercular patients was also recorded. The history of tuberculosis treatment by the patient was noted. Modified Prasad classification was used to assess the economic status of the patients. ${ }^{[5]}$ A chest X-ray (posterior-anterior view) was obtained to assess the pulmonary involvement in all the patients of hydropneumothorax. Directly observed treatment short-course, according to the Revised National Tuberculosis Control Program for India ${ }^{[6]}$ was used for the treatment of drug-sensitive tuberculosis.

In all cases, straight-line dullness, immediate shifting dullness, coin test, and succussion splash were noted. ${ }^{[3,7]}$ The examination was done in a sitting or standing position. For the shifting dullness, the patient was first examined in a sitting position and later was asked to lie supine. This examination was performed by two researchers (SKS and PY). In case of a discrepancy in findings, the cases were examined by the third researcher (KKT), and his findings were considered final.

Underwater sealed chest tube drainage was done under local anesthesia. The safe triangle was marked. The safe triangle is an area bordered by the anterior border of the latissimus dorsi, the lateral border of the pectoralis major, and a line superior to the horizontal level of the nipple, with its apex toward the axilla. This is the site that coincides with the fifth or sixth space in the midaxillary line. ${ }^{[8]}$ The chest tube was removed when the affected lung became fully expanded with no air leak and daily intercostal tube drain (ICD) drainage of $<100 \mathrm{~mL}$. ${ }^{[8]}$

Tuberculosis was confirmed by the presence of acid-fast bacilli (AFB) in the sputum by the Ziehl-Neelsen technique. A diagnosis of pulmonary tuberculosis was ruled out if the sputum for AFB was negative on two separate occasions, and the patients did not show a positive response to 2 to 3 weeks of an antibiotics course. They were further confirmed as a case of pulmonary tuberculosis if their clinical features improved with treatment with antitubercular drugs. Pleural fluid was also subjected to routine microscopy, biochemical analyses (proteins, glucose, and lactate dehydrogenase). Light's criteria were used to classify pleural fluid in exudate and transudate pleural effusion. Xpert MTB/ RIF (Xpert) (Cepheid, Sunnyvale, CA) for Mycobacterium tuberculosis was also carried out in all cases. Culture and sensitivity test for Mycobacterium was not done because of its nonavailability.

\section{Statistical analysis}

All data were initially entered in Microsoft Excel 2016 (Microsoft Corporation, Microsoft Excel [Internet]. 2016. Available from: https://office.microsoft.com/excel) and later analyzed using the same software. Mean, standard deviation, and frequency (percentage) were used to describe the results of this descriptive study.

\section{RESULTS}

Fifty-two patients diagnosed with hydropneumothorax were included in this study. The mean age of the patients was $34.17 \pm 11.6$ years. Thirty-nine $(75 \%)$ patients were male [Table 1]. Breathlessness and cough were the most common presenting feature seen in $50(96.2 \%)$ and $49(94.2 \%)$ patients, respectively. Fever was seen in 47 (90.3\%), chest pain in $48(92.3 \%)$, weight loss and loss of appetite in $30(57.7 \%)$ patients, and hemoptysis in $11(21.2 \%)$ patients. History of antitubercular treatment was present in $20(38.5 \%)$ patients. Twenty-five (48.1\%) patients gave a history of contact with tuberculosis patients. Hypertension, diabetes mellitus, and breast carcinoma were present as a comorbidity in $7(13.46 \%)$, $4(7.8 \%)$, and $1(1.9 \%)$ patients, respectively.

Shifting dullness, coin test, and straight-line dullness were demonstrable in all patients. However, a succussion splash was demonstrable in 45 (86.5\%) patients only. Sputum for AFB was positive in $17(32.7 \%)$ patients. Sputum Xpert MTB/RIF was positive in $26(50 \%)$ patients, and among them, $3(5.8 \%)$ were found to be resistant to rifampicin. Pleural fluid Xpert TB was positive in $9(17.3 \%)$ patients. All the patients were found to have exudative pleural effusion by Light's criteria. Pleural fluid biochemistry showed protein of $4 \pm 0.4 \mathrm{~g} / \mathrm{dl}$ and glucose of $79 \pm 20.7 \mathrm{~g} / \mathrm{dl}$. Pleural fluid cytology was acute inflammatory

\begin{tabular}{lc}
\hline Table 1: Sociodemographic characteristics of patients \\
\hline Parameter & $\boldsymbol{n}(\%)$ \\
\hline Age (years) & \\
$12-29$ & $22(42.3)$ \\
$30-49$ & $21(40.4)$ \\
$>50$ & $9(17.3)$ \\
Sex & \\
Male & $39(75)$ \\
Female & $13(25)$ \\
Modified Prasad classification & \\
Class 1 & $0(0)$ \\
Class 2 & $9(17.3)$ \\
Class 3 & $10(19.2)$ \\
Class 4 & $14(26.9)$ \\
Class 5 & $19(36.5)$ \\
Educational status & \\
Illiterate & $12(23.1)$ \\
Primary & $9(17.3)$ \\
High school & $5(9.6)$ \\
Intermediate & $12(23.1)$ \\
Graduates & $11(21.2)$ \\
Postgraduate & $3(5.8)$ \\
Marital status & \\
Married & $42(80.8)$ \\
Unmarried & $10(19.2)$ \\
Smoking status & \\
Active smoker & $27(51.9)$ \\
Nonsmoker & $25(48.1)$ \\
History of contact with tubercular patients & $25(48.1)$ \\
History of antitubercular treatment in past & $20(38.5)$ \\
\hline & \\
&
\end{tabular}


in $15(28.9 \%)$, chronic inflammatory in $31(59.6 \%)$, and malignant cells were detected in $6(11.5 \%)$ patients.

Tuberculosis was the most common etiological diagnosis seen in $32(61.5 \%)$ patients. Acute bacterial infection was found in $14(26.9 \%)$ cases. In the rest of the cases, malignancy was the cause of hydropneumothorax [Table 2]. Adenocarcinoma of the lung was the cause of malignancy in five cases, whereas one case was diagnosed case of breast carcinoma.

The chest X-ray showed left-sided hydropneumothorax in $27(51.9 \%)$ patients. Cavitation was the most common chest $\mathrm{X}$-ray finding in $34(65.4 \%)$ cases. Infiltration, consolidation, fibro-destructive lesion, mediastinal lymphadenopathy, and mass were the other chest X-ray findings seen in $27(51.9 \%)$, 18 (34.6\%), $16(30.8 \%), 7(13.5 \%)$, and 6 (11.6\%) cases, respectively.

First-line antitubercular treatment was given to $28(53.9 \%)$ tuberculosis patients. Antitubercular treatment for multidrug-resistant tuberculosis was given to $3(5.8 \%)$ patients. Among the tubercular patients, 7 (13.5\%) were receiving antitubercular treatment when they developed hydropneumothorax, while in 24 (46.2\%) patients, antitubercular treatment was prescribed after a diagnosis of hydropneumothorax was made.

Hydropneumothorax cases were managed with ICD insertion. Bronchopleural fistula was seen in $23(44.2 \%)$ cases. The mean duration of tube insertion was $21.3 \pm 10.6$ days in 51 patients. One patient of hydropneumothorax died during the treatment. All the malignant cases underwent talc pleurodesis for malignant pleural effusion. Fifty-one patients showed complete resolution after the intercostal tube insertion [Table 3]. Chest tube-related complications were seen in $9(17.3 \%)$ cases. These

\begin{tabular}{lc}
\hline Table 2: Causes of hydropneumothorax & \\
\hline Etiology & $\boldsymbol{n}(\%)$ \\
\hline Bacterial & $14(26.9)$ \\
Tuberculosis & $32(61.5)$ \\
Non-MDR & $28(53.9)$ \\
MDR & $3(5.8)$ \\
Old healed tuberculosis & $1(1.9)$ \\
Malignancy & $6(11.5)$ \\
Total & $52(100)$ \\
\hline MDR: Multidrug resistant &
\end{tabular}

\begin{tabular}{lc}
\hline $\begin{array}{l}\text { Table 3: Duration of the requirement of intercostal } \\
\text { drainage based on etiology }\end{array}$ \\
\hline Etiology & Days \\
\hline Bacterial & $11.9 \pm 3.7$ \\
Tuberculosis & $27.1 \pm 9.0$ \\
MDR & $31.3 \pm 11.2$ \\
Non-MDR & $26.2 \pm 8.7$ \\
Old healed tuberculosis & 39 \\
Malignancy & $10.8 \pm 5.3$ \\
\hline MDR: Multidrug resistant
\end{tabular}

included subcutaneous emphysema (9.5\%), dislodgment of the tube $(3.9 \%)$, and surgical site infection $(3.9 \%)$.

\section{Discussion}

Hydropenumothorax is not an uncommon entity in Northern India. The mechanism of development of hydropneumothorax may be considered the combination of the mechanism of development of pleural effusion and pneumothorax. It can develop due to the rupture of the tuberculous cavity, due to the rupture of subpleural lung abscess, iatrogenic due to aspiration of fluid in pleural effusion, and due to superadded infection in the long-standing intercostal tube in pneumothorax. It may also develop due to penetrating chest injury. Other causes of hydropneumothorax include rupture of necrotic neoplastic tissue and necrotic tumor nodule within the pleural cavity, necrosis of the subpleural metastasis, and secondary infection due to obstruction by the tumor itself. ${ }^{[9]}$

In our study, the most common cause of hydropneumothorax was tuberculosis $(61.5 \%)$, followed by bacterial infection and malignancy. A study by Kasargod and Awad ${ }^{[10]}$ also found tuberculosis $(81 \%)$ to be the most common cause of hydropneumothorax, followed by a bacterial infection (14\%). The same study detected malignancy as the cause of hydropneumothorax in $3.5 \%$ of cases, but in this study, it was seen in $11.5 \%$ of cases. All malignancy types except for one were adenocarcinoma. In one case, the recurrence of breast carcinoma was the etiology for hydropneumothorax. Recurrence of breast carcinoma causing hydropneumothorax is rare but has been reported in the literature. ${ }^{[11]}$ Xpert MTB/ RIF in pleural fluid showed positivity in $17 \%$ of the cases. It was similar to the study by Kasargod and Awad, ${ }^{[10]}$ who demonstrated AFB in $14 \%$ of cases. In this study, pleural fluid was not subjected to AFB examination. Instead, Xpert MTB/ RIF was done, which is a more sensitive test. ${ }^{[12]}$

Most of the patients in our study presented with complaints of breathlessness $(96.2 \%)$ and cough $(94.2 \%)$. The reason for that presentation is due to pleural involvement in hydropneumothorax, causing the collapse of the lung, leading to ventilation-perfusion mismatch. ${ }^{[10]}$ A similar study on hydropneumothorax also found breathlessness (95\%) and cough (93\%) as the main complaint in the majority of patients. ${ }^{[10]}$ Cough and breathlessness were also the most common presenting features in the study done by Shamaei et al. ${ }^{[13]}$ and Khan et al. ${ }^{[14]}$ although their studies were done on patients of pneumothorax. This emphasizes that patients with pleural involvement usually present with breathlessness and cough. However, Blanco-Perez et al. ${ }^{[15]}$ in their study on the patients of tubercular pneumothorax reported chest pain $(90 \%)$, dyspnea (45\%), cough (45\%), and fever (36\%) as the most frequently reported symptoms. In our study, fever, chest pain, and weight loss and loss of appetite were seen in $90.3 \%, 92.3 \%$, and $30 \%$ of cases, respectively, probably because tuberculosis and bacterial infection were the main etiology causing the hydropneumothorax in our cases $(89 \%)$. 
During the auscultation of the chest in a patient of hydropneumothorax, sudden movement of the chest causes movement of the fluid producing a splashing sound known as the succussion splash (Hippocratic succussion splash). ${ }^{[16]}$ It is considered as one of the cardinal signs of hydropneumothorax. It is not specific for hydropneumothorax as it can be heard in any hollow viscus containing fluid. In the case of thorax, it can be heard in hydropneumothorax, fluid, and air present in a large cavity, and herniation of abdominal contents such as the stomach and large intestine in the left thorax because of eventration of diaphragm. ${ }^{[17,18]}$ Normally, the stomach can also produce succussion splash up to $2 \mathrm{~h}$ of ingestion of fluid and food. However, abnormally, it can be heard in pyloric obstruction, grossly dilated intestine due to advanced intestinal obstruction, and in paralytic ileus. ${ }^{[17]}$ In our study, it was not heard in $14 \%$ of cases only. The reason for nonelicitation of sound might be due to a lesser amount of fluid present in the pleural cavity along with a thick chest wall causing the nontransmission of sound to the stethoscope.

In our study, hydropneumothorax was more common on the left side. This was similar to other Indian studies, which showed left-sided spontaneous pneumothorax more common than right-sided ones. ${ }^{[19,20]}$

ICD was inserted in all the cases, and the mean duration of ICD was $21.3 \pm 10.6$ days in 51 patients. Tuberculosis patients showed a longer duration of the requirement of $\operatorname{ICD}(27.1 \pm 9.0$ days $)$ in comparison to the hydropneumothorax due to bacterial and malignant origin, which showed $11.9 \pm 3.7$ and $10.8 \pm 5.3$ days, respectively. The mean duration of ICD was 24.8 days $( \pm 13.1)$ in the study done by Kasargod and Awad. ${ }^{[10]}$ Previous studies were done on tuberculosis-associated pneumothorax also found the longer duration of ICD drainage, and it is suitable to delay the surgery needed for persistent drainage from ICD ${ }^{[17]}$ A study was done in the same institution on tuberculosis-associated pneumothorax found the mean duration of intercostal drainage was $17.14 \pm 6.37$ days (range: 6-32 days). ${ }^{[21]}$

\section{Limitations}

A small sample size is the main limitation of this study. The data are not representative of the whole community as the study was conducted at one tertiary care center. The majority of the patients (35 out of 51) did not return for follow-up, and therefore, the recurrence rate could not be analyzed. However, none of the follow-up patients showed recurrence of hydropneumothorax.

\section{Conclusion}

Tuberculosis is the most common cause of hydropneumothorax. It can be the presenting feature of tuberculosis, and at times, it can develop during the antitubercular treatment. The mainstay of treatment for hydropneumothorax is the underwater seal intercostal drainage. Apart from this, antitubercular drugs for the treatment of tuberculosis and antibiotics for the treatment of bacterial etiology should be given. Tuberculosis-associated hydropneumothorax requires a higher longer duration of hospital stay in comparison to nontubercular causes.

\section{Financial support and sponsorship}

Nil.

\section{Conflicts of interest}

There are no conflicts of interest.

\section{REFERENCES}

1. Goodman LR. Principles of Chest Roentgenology a Programmed Text. $2^{\text {nd }}$ ed.. Philadelphia, Pennsylvania: Saunders; 1999.

2. Ortega C, Gonzales C, Soto-Martinez ME, Yock-Corrales A. Hydropneumothorax in children: A rare complication of a bacterial pneumonia. Case Rep Pediatr 2016;2016:8097105.

3. Basanta H, Rao VD. Bedside Respiratory Medicine. $1^{\text {st }}$ ed.. Hyderabad, India: Paras Medical Books Pvt. Ltd.; 2013.

4. Girithari G, Dos Santos IC, Claro E, Belykh S, Matias D, Santos O. The Hippocratic splash. Eur J Case Rep Intern Med 2018;5:000975.

5. Dudala SR, Arlappa N. An updated Prasad's socio-economic status classification for 2013. Int J Res Dev Health 2013;1:26-7.

6. Revised Technical \& Operational Guidelines for TB. Available from: http://www.tbcindia.nic.in/WriteReadData/Revised\%20Technical\%20 and\%20Operational\%20Guidelines/files/assets/basic-html/page-1. html\#. [Last accessed on 2020 Jun 11].

7. Kundu AK. Bed Side Clinics in Medicine. $7^{\text {th }}$ ed.., Vol. 1. Kolkata, India: Academic Publishers; 2014.

8. Kumar A, Dutta R, Jindal T, Biswas B, Dewan RK. Safe insertion of a chest tube. Natl Med J India 2009;22:192-8.

9. Tsukamoto T, Satoh T, Yamada K, Nagasawa M. Primary lung cancer presenting as spontaneous pneumothorax. Nihon Kyobu Shikkan Gakkai Zasshi 1995;33:936-9.

10. Kasargod V, Awad NT. Clinical profile, etiology, and management of hydropneumothorax: An Indian experience. Lung India 2016;33:278-80.

11. Huang CY, Soriano LF, Wakely S, Cavill S, Zrelec S. Hydropneumothorax and intrapulmonary metastases secondary to breast cancer recurrence. Br J Hosp Med (Lond) 2018;79:533.

12. Du J, Huang Z, Luo Q, Xiong G, Xu X, Li W, et al. Rapid diagnosis of pleural tuberculosis by Xpert MTB/RIF assay using pleural biopsy and pleural fluid specimens. J Res Med Sci 2015;20:26-31.

13. Shamaei M, Tabarsi P, Pojhan S, Ghorbani L, Baghaei P, Marjani M, et al. Tuberculosis-associated secondary pneumothorax: A retrospective study of 53 patients. Respir Care 2011;56:298-302.

14. Khan N, Jadoon H, Zaman M, Subhani A, Khan AR, Ihsanullah M. Frequency and management outcome of pneumothorax patients. J Ayub Med Coll Abbottabad 2009;21:122-4.

15. Blanco-Perez J, Bordón J, Piñeiro-Amigo $\mathrm{L}$, Roca-Serrano $\mathrm{R}$, Izquierdo R, Abal-Arca J. Pneumothorax in active pulmonary tuberculosis: Resurgence of an old complication? Respir Med 1998;92:1269-73.

16. Chung SN. Clinical Methods in Medicine: Clinical Skills and Practices. New Delhi: Jaypee Brothers; 2008.

17. Sarkar M, Madabhavi I, Niranjan N, Dogra M. Auscultation of the respiratory system. Ann Thorac Med 2015;10:158-68.

18. Gayatridevi Y, Usharani N, Premkumar A, Sambasivarao G, Kumari VS, Joshua S. Clinical profile of spontaneous pneumothorax in Adults: A retrospective study. Indian J Chest Dis Allied Sci 2015;57:219-23.

19. Dhua A, Chaudhuri AD, Kundu S, Tapadar SR, Bhuniya S, Ghosh B, et al. Assessment of spontaneous pneumothorax in adults in a tertiary care hospital. Lung India 2015;32:132-6.

20. Jindal S. Textbook of Pulmonary and Critical Care Medicine. New Delhi: Jaypee Brothers Medical Publishers; 2011.

21. Singh SK, Tiwari KK. Analysis of clinical and radiological features of tuberculosis associated pneumothorax. Indian J Tuberc 2019;66:34-8. 